1278 Archives of Disease in Childhood, 1987, 62

\title{
Dominantly inherited glomerulonephritis and an unusual skin disease
}

\author{
M C SHERWOOD, ${ }^{*} \mathrm{~J}$ R PINCOTT,${ }^{*}$ F J GOODWIN, $\dagger$ AND M J DILLON* \\ ${ }^{*}$ Queen Elizabeth Hospital for Children, + London Hospital, and ${ }^{*}$ Hospital for Sick Children, Great Ormond \\ Street, London
}

SUMMARY An unusual association of uncommon facies including telangiectasia in a butterfly distribution, a similar skin lesion on extensor areas, sparse hair, and membranoproliferative glomerulonephritis is described in a 4 year old boy and his father. The mode of inheritance of these features seems to be autosomal dominant.

A family is described in which the father and his only son have an unusual association of anomalies. These comprise facial telangiectasia in a pattern not described in other syndromes; telangiectasia of some extensor surfaces; sparse hair, eyebrows, and eyelashes; and membranoproliferative glomerulonephritis. These features seem to be inherited in

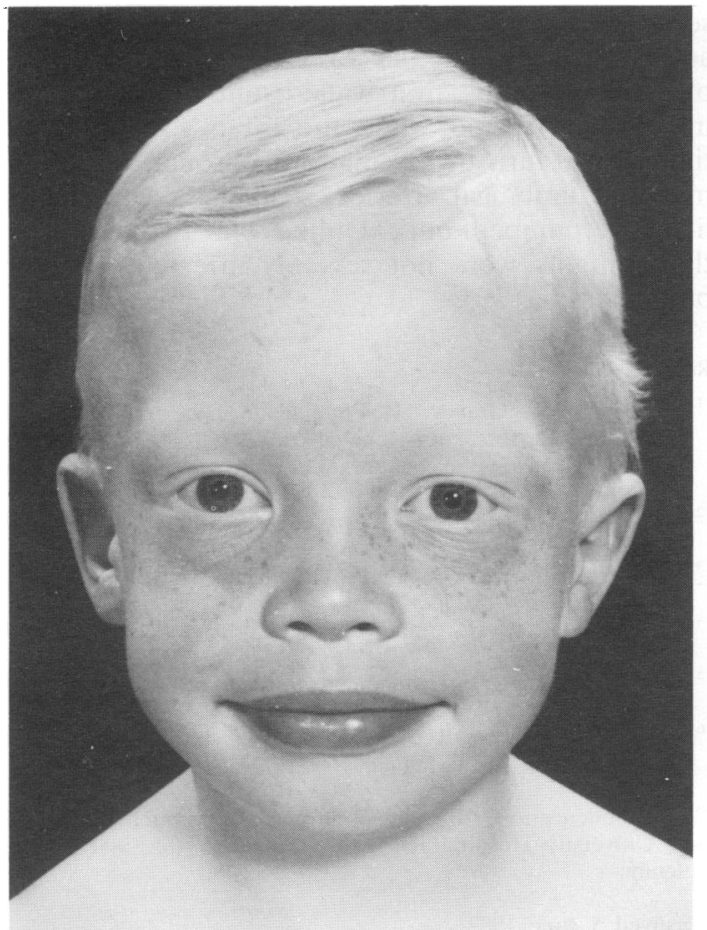

an autosomal dominant fashion, and after an exhaustive search we can find no evidence that this association has been previously described.

\section{Case report}

A 4 year old boy admitted for tonsillectomy and adenoidectomy was found on routine urine testing to have mild proteinuria and microscopic haematuria. There had been no frank haematuria but on two occasions his urine had been pink. He had no dysuria. Two months previously he had had several undiagnosed febrile illnesses. An audiogram performed four months earlier was normal.

He was born at term by caesarean section following a normal pregnancy, and weighed $3200 \mathrm{~g}$. A pyloromyotomy had been performed for pyloric

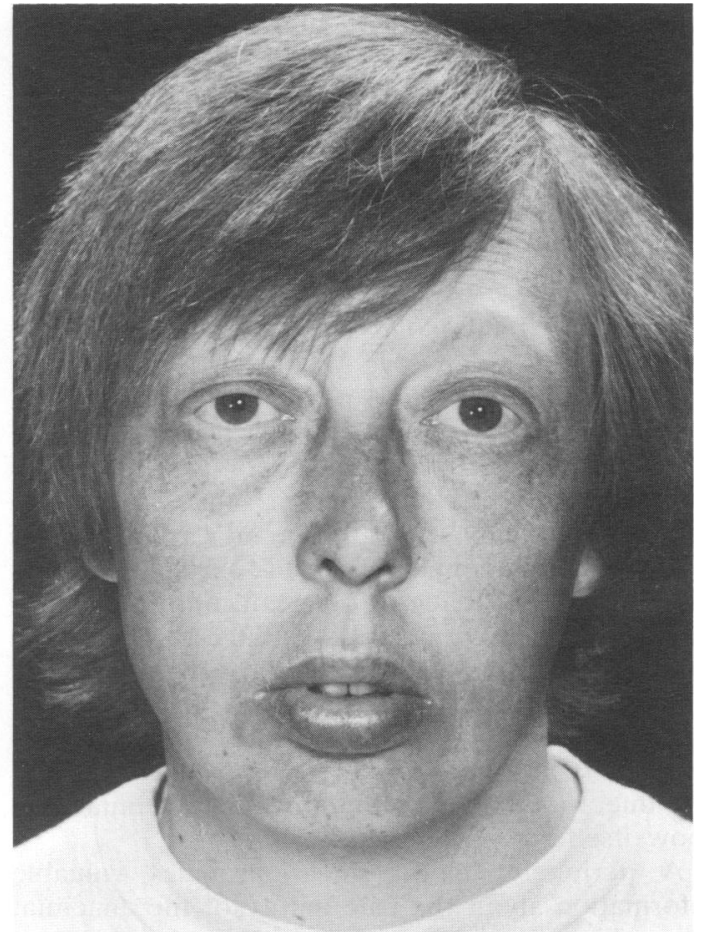

Fig 1 Facial appearances of father and son showing characteristic features. 
stenosis when he was 1 month old. Subsequent development had been normal.

Family history showed that his parents were unrelated, but his father had end stage renal failure and was hypertensive. He also had a dermatological disease of uncertain aetiology that was similar to the skin lesion of the Rothmund-Thomson syndrome. The father's disease had been diagnosed at 22 years of age and a renal biopsy had been performed eight years later by which time he had been in end stage renal failure. The biopsy specimen showed features of end stage kidney disease which could have been either membranoproliferative glomerulonephritis or focal segmental glomerulosclerosis. Electron microscopy pictures showed focal subendothelial deposits of electron dense granular material, but no evidence of Alport's nephritis. When he was 33 years old he had undergone renal transplantation.

Physical examination of the son showed a well grown boy, on the 50th centile for weight and the 25th for height, with a striking facial appearance closely resembling his father's (fig 1). He had epicanthic folds, hypertelorism, and fine photosensitive telangiectasia in a butterfly pattern on the upper cheeks. Similar telangiectasia. was also present on the dorsal aspects of his fingers and elbows. He had blue eyes; pale, fine, short eyebrows and eyelashes, and sparse blonde hair of normal texture with a receding hairline. His mouth, teeth, and nails were normal. He was normotensive, no renal masses were palpable, and both testes were descended.

Analysis of a midstream specimen of urine consistently showed 9-50 red cells per high power field, and protein concentration varied from negative to +++ on Albustix testing. The urinary albumin: creatinine ratio varied from 0.5 to 1.99 (normal $<0 \cdot 1)$. Antistreptolysin and antideoxyribonuclease titres were within normal limits. Hepatitis B surface antigen screening was negative as were tests for autoantibodies and $\mathrm{C} 3$ nephritic factor. Coagulation studies, immunoglobulin concentrations, C3, C4, and $\mathrm{CH}_{50}$ activity, chromosome analysis, and renal ultrasonography were normal. Plasma creatinine concentrations were consistently mildly raised (55-
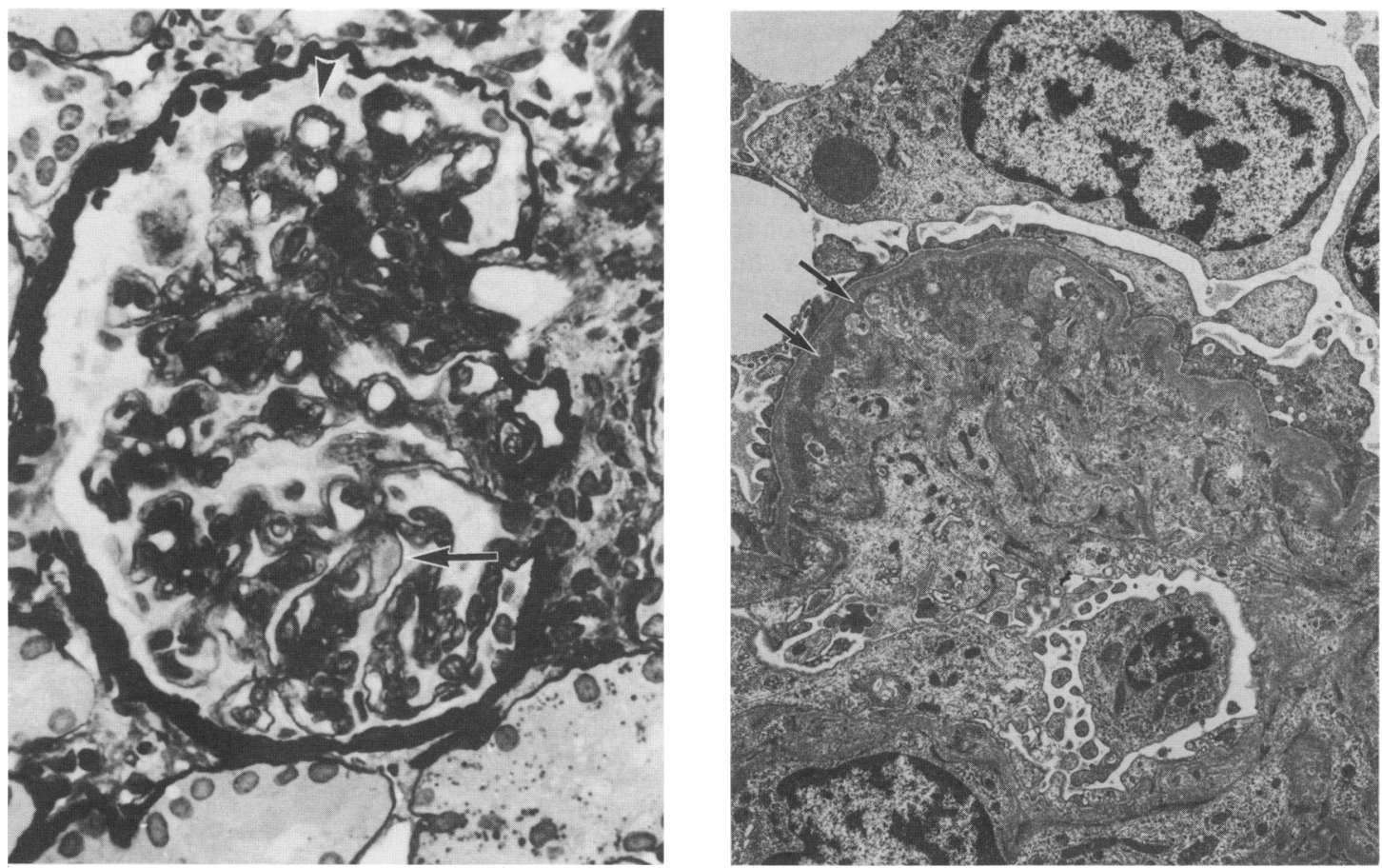

Fig 2a Glomerulus shows diffuse mesangial proliferation with many double contours (arrow head) and subendothelial deposits (arrow). (Methenamine silver.)

Fig 2b Single capillary loop with severely narrowed lumen (bottom); mesangial interposition between basement membrane and endothelium; electron dense deposits (arrows) beneath basement membrane, with fusion of overlying epithelial foot processes. (Electron photomicrograph.) 
$96 \mu \mathrm{mol} / \mathrm{l})$ but the glomerular filtration rate was 140 $\mathrm{ml} /$ minute $/ 1 \cdot 73 \mathrm{~m}^{2}$. Renal biopsy was undertaken at the age of 5 years and 2 months.

The biopsy specimen contained 70 glomeruli which were uniformly abnormal (fig 2a) and although not enlarged showed diffuse mesangial proliferative change. Capillary loops were thickened with 'double contour' formation on silver staining and subendothelial deposits were seen. The glomerular changes were accompanied by a mild degree of tubular atrophy and a localised increase in interstitial connective tissue. Blood vessels were normal.

Immunofluorescence of $\operatorname{IgA}, \operatorname{IgG}, \operatorname{IgM}, \mathrm{Clq}, \mathrm{C} 3$, and fibrin was negative and electron microscopy (fig 2b) showed mesangial interposition causing severe narrowing of capillary loops. There were widespread subendothelial deposits, some extremely large, and a moderate fusion of epithelial foot processes. Membranoproliferative glomerulonephritis of subendothelial deposit type was diagnosed.

\section{Discussion}

This unusual association of dermatological abnormality and renal disease, inherited in an apparently dominant manner, does not seem to be well known. The precise nature of the dermatological lesion is still in some doubt; it is similar to the telangiectasia seen in Rothmund-Thomson syndrome but there was no evidence in the child or his father of the characteristic depigmentation and atrophy. ${ }^{1}$ A similar photosensitive facial telangiectasia in a butterfly distribution occurs in Bloom's syndrome, in which there is a disorder of DNA stability. ${ }^{2}$ Chromosome studies in this patient failed to show any abnormality. Cockayne's syndrome also has a similar facial dermatological lesion and may have associated renal disease, but histological examination of renal biopsy specimens in these patients showed hyalinisation of glomeruli, tubular atrophy, and interstitial fibrosis. ${ }^{3}$ The other typical clinical features of these conditions were not apparent in the patient or his father. The mode of inheritance in Rothmund-Thomson, Bloom's, and Cockayne's syndromes is thought to be autosomal recessive and this does not seem to apply in this family.

There are several diseases associated with membranoproliferative glomerulonephritis, but hitherto skin lesions as described here have not been among them. Although similarities exist between our patients and the sibship described by Mampaso et al with mesangial proliferative glomerulonephritis, diffuse glomerular deposits of IgM and C3, RothmundThomson syndrome, and Clq deficiency the syndromes seem to be distinct. ${ }^{4}$ Membranoproliferative glomerulonephritis has been recorded in siblings ${ }^{5}$ but the only previous report that clearly shows that it can be a genetically determined disease was by Stutchfield et al. ${ }^{6}$ The disorder that they described was $X$ linked without a skin rash and obviously distinguishable from that seen in our family, although it also had a normal complement profile.

Because the father's only renal biopsy specimen showed end stage renal disease it is impossible to be certain that the father's renal disease is identical with that of his son, but it would not seem an unreasonable assumption that it is. The progressive nature of the father's condition prompted us to consider trying to modify the progression of the child's glomerulonephritis. In view of his stable renal function, however, he is currently not receiving treatment.

The autosomal dominant inheritance of this condition implies that there is a one in two risk of the offspring of this boy being affected. At present no means of definite prenatal diagnosis is available. Even if it were, it would probably offer little advantage in view of the slow progression of the renal disease into adult life, and the possibility of treatment by renal transplantation.

\section{References}

' Oates RK, Lewis MB, Walker-Smith JA. The RothmundThomson syndrome; case report of an unusual syndrome. Aust Paediatr J 1971;7:103-7.

2 Sawitsky A, Bloom D, German J. Chromosomal breakage and acute leukaemia in congenital telangiectasia erythema and stunted growth. Ann Intern Med 1966;65:487-95.

${ }^{3}$ Ohno T, Hirooka M. Renal lesions in Cockayne's syndrome. Tohoku J Exp Med 1966;89:151-61.

${ }^{4}$ Mampaso F, Ecija J, Fogue L, Moneo I, Gallego N, LeyvaCobian F. Familial Clq deficiency in 3 siblings with glomerulonephritis and Rothmund-Thomson syndrome. Nephron $1981 ; 28: 179-85$.

5 Berry PL, McEnery PT, McAdams AJ, West CD. Membranoproliferative glomerulonephritis in two sibships. Clin Nephrol 1981;16:101-6.

' Stutchfield PR, White RHR, Cameron AH, Thompson RA, Mackintosh P, Wells L. X-linked mesangiocapillary glomerulonephritis. Clin Nephrol 1986;26:150-6.

Correspondence to Dr MJ Dillon, Renal Unit, Hospital for Sick Children, Great Ormond Street, London WC1N 3JH.

Received 11 June 1987 